\title{
Preface to the Special Issue Honoring Bob Ledeen
}

\author{
Robert K. Yu
}

Received: 23 March 2012/Accepted: 27 March 2012/Published online: 8 April 2012

(C) Springer Science+Business Media, LLC 2012

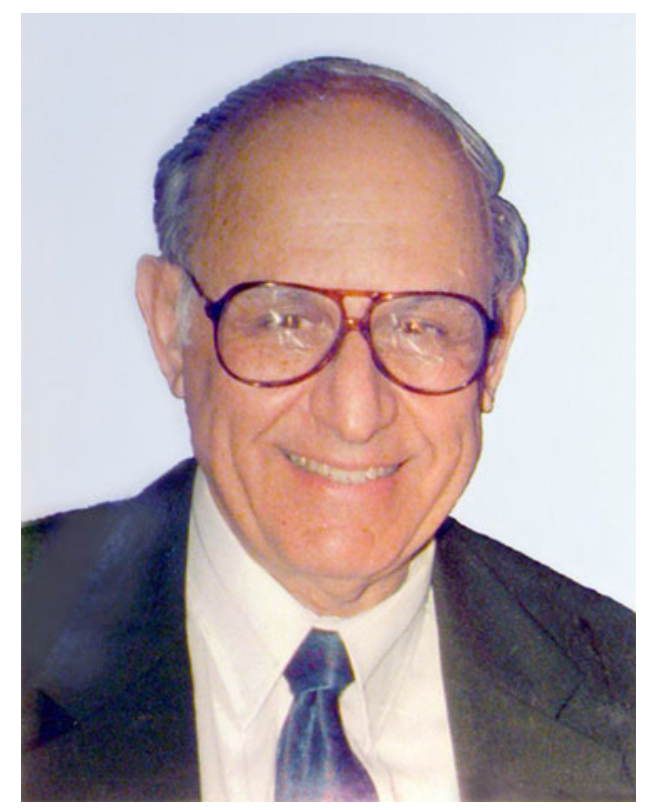

Bob Ledeen

It is a special privilege that we have compiled a Special Issue of Neurochemical Research to honor Dr. Robert W. Ledeen, Professor of Neurology and Neurosciences, University of Medicine and Dentistry of New Jersey, Newark, New Jersey, USA. A total of 23 articles from contributors from all over the world are included in this

Special Issue: In Honor of Bob Leeden.

\section{R. K. Yu ( $\square)$}

Institute of Molecular Medicine and Genetics, Institute of Neuroscience, Medical College of Georgia, Georgia Health Sciences University, Augusta, GA 30912, USA

e-mail: ryu@georgiahealth.edu issue, and they cover a wide range of topics, including neurochemistry, neurobiology, glycobiology, signal transduction, and developmental neurobiology. Dr. Ledeen is no doubt one of the most prominent scientists in neurochemistry and glycobiology and his seminal work has greatly influenced these fields for many years.

Dr. Ledeen received a BS degree in chemistry at the very early age of 20 from the University of California, Berkeley and subsequently obtained his $\mathrm{PhD}$ degree in organic chemistry in 1953 from the University of Oregon, Corvallis. Postdoctoral training at the University of Chicago was interrupted by military service and then resumed at Mt. Sinai and Albert Einstein College of Medicine in 
New York. He was appointed by Dr. Saul Korey as an instructor in 1961, in the Einstein Department of Neurology, eventually becoming a tenured professor. He credits Saul Korey as the one who introduced him to gangliosides, of interest at that time in relation to Tay-Sachs and other lipid storage diseases. At Einstein, he and Drs. William T. Norton and Kunihiko Suzuki among others, rapidly established a prominent research and educational program in neurochemistry. In 1991, he was recruited to the University of Medicine and Dentistry of New Jersey as Professor and Director of Neurochemistry in the Department of Neurosciences, and there has continued his enduring efforts in neurochemical research.

Dr. Ledeen has been involved in glycolipid research for half a century ("believe it or not", he says.). His work has continued to influence the direction of the field till today. $\mathrm{He}$ was the first to establish the correct structure of Tay-Sachs ganglioside (GM2) in 1965. He subsequently elucidated the ketosidic configuration of sialic acid in sialoglycoconjugates in 1969. These early contributions were followed by a series of careful studies on the cellular and subcellular distribution of gangliosides in the nervous system, including the demonstration of gangliosides in neuronal and glial membranes, myelin, synaptic vesicles, and growth cones. He further demonstrated fast axonal transport as the distribution mechanism of gangliosides and other lipids to axonal and nerve ending membranes. These studies led to work on the neuritogenic effects of gangliosides in the nervous system, adding to the pioneering work of Dr. Dominick Purpura and others. He further made the fundamental discovery that GM1 ganglioside in the plasma membrane modulates the calcium concentration in neuronal cells, which accounts in part for its biological effects in promoting neuritogenesis. More recently he made another surprising discovery that GM1 ganglioside is also present in the nuclear membrane where it occurs in close association with the sodium-calcium exchanger protein that regulates intracellular calcium homeostasis. Those and other findings are contributing to the growing recognition of the importance of intracellular gangliosides in regulating a number of neuronal functions, leading to his current exciting work on the beneficial role of GM1 in relation to Parkinson's disease.

In addition to the above, Dr. Ledeen has also carried out numerous fundamental studies on the chemistry and metabolism of myelin metabolizing enzymes. His discovery of myelin-associated $\mathrm{G}$ proteins linked to cholinergic receptors is particularly noteworthy as it demonstrated for the first time the existence of signaling pathways in myelin. Subsequent work revealed the presence of aspartoacylase in myelin and its role in providing acetyl groups for lipid biosynthesis within that membrane. These studies contributed substantially to an altered view of metabolic activity within myelin, which had for many years been considered as an inert membrane.

After decades-long devotion to the study of ganglioside function in the nervous system, Dr. Ledeen's recent interests have turned to the immune system where his group has sought to elucidate the mechanism of immune suppression and the reasons for its failure in autoimmune disorders. This work revealed the role of GM1 in effector T cells which, when cross-linked by galectin-1 from regulatory $\mathrm{T}$ cells, opens TRPC5 calcium channels thereby inactivating and eliminating autoreactive effector $\mathrm{T}$ cells. His group is actively probing the potency of GM1-galectin-1 interaction in $\mathrm{T}$ cells of autoimmune patients, with an eye toward potential new therapies.

Neurochemical Research conferred an unusual honor on Bob a while back in publishing a poem he wrote on the occasion of his colleague Bill Norton's retirement, in which he imagined Bill reminiscing on the relative ease of grant funding early in his career compared to the current situation:

Sweet milk did flow from the NIH cow,

Playing the grant game was the cat's meow;

But the times they have changed, my colleagues are

blue,

What once gave us milk now gives us 'mooo'.

Bob confides to his friends that he is more excited than ever about research and the progress so many are making in the glycosphingolipid field. It is remarkable that he has maintained such a consistent level of scientific excellence for so many years, and continues as vigorously as ever. It should be noted that his research has been supported by numerous funding agencies for many years including virtually continuous NIH funding from the beginning of his ganglioside studies. An acute understanding of the problem, a mastery of technology and experimental design, and a high level of intelligence and insight mark his science. He has indeed set an example for many of us in the field to follow.

Representative publications of Dr. Ledeen (from a total of 175 full papers)

1. R. Ledeen and K. Salsman, "Structure of the Tay-Sachs ganglioside". Biochemistry 4, 2225-2233 (1965).

2. R.K. Yu and R. Ledeen, "Configuration of the ketosidic bond of sialic acid". J. Biol. Chem. 244, 1306-1313 (1969).

3. R.K. Yu and R. Ledeen, "Gas-liquid chromatographic assay of lipid-bound sialic acids: Measurement of gangliosides in brain of several species". J. Lipid Res. 11, 506-516 (1970).

4. R.K. Yu and R.W. Ledeen, "Gangliodises of human, bovine and rabbit plasma". J. Lipid Res. 13, 680-686 (1972). 
5. D.S. Forman and R.W. Ledeen, "Axonal transport of gangliosides in the goldfish optic nerve". Science 177, 630-633 (1972).

6. R.W. Ledeen, R.K. Yu and L.F. Eng, "Gangliosides of human myelin: Sialosylgalactosylceramide $\left(\mathrm{G}_{7}\right)$ as a major component". J. Neurochem. 21, 829-839 (1973).

7. R.K. Yu, R.W. Ledeen, D.C. Gajdusek and C.J. Gibbs, "Ganglioside changes in slow virus diseases: Analyses of chimpanzee brains infected with Kuro and Creutzfeldt-Jakob agents”. Brain Res. 70, 103-112 (1974).

8. R.K. Yu, R.W. Ledeen and L.F. Eng, "Ganglioside abnormalities in multiple sclerosis" J. Neurochem. 23, 169-1714 (1974).

9. R.W. Ledeen, "Ganglioside structures and distribution: are they localized at the nerve ending" J. Supramolec. Struct. 8, 1-17 (1978).

10. J.E. Haley, L.J. Tirri and R.W. Ledeen, "Axonal transport of lipids in the rabbit optic system". J. Neurochem. 32, 727-734 (1979).

11. F.B. Cochran, Jr., R.K. Yu and R.W. Ledeen, "Myelin gangliosides in vertebrates". J. Neurochem. 39, 773-779 (1982).

12. M.C. Byrne, R.W. Ledeen, F.J. Roisen, G. Yorke, and J. R. Sclafani, "Ganglioside-induced neuritogenesis: verification that gangliosides are the active agents, and comparison of molecular species". J. Neurochem. 41, 1214-1222 (1983).

13. T. Kunishita and R.W. Ledeen, "Phospholipid biosynthesis in myelin: presence of CTP: ethanolaminephosphate cytidylyltransferase in purified myelin of rat brain". J. Neurochem. 42, 326-333 (1984).

14. R.W. Ledeen, "Lipid-metabolizing enzymes of myelin and their relation to the axon". J. Lipid Res. 25, 1548-1554 (1984).

15. J.N. Larocca, R.W. Ledeen, B. Dvorkin, and M.H. Makman, "Muscarinic receptor binding and muscarinic receptor-mediated inhibition of adenylate cyclase in rat brain myelin." J. Neurosci. 7, 38693876 (1987).

16. R.W. Ledeen, S.M. Parsons, M.F. Diebler, M. Sbaschnig-Agler, and S. Lazereg, "Ganglioside composition of synaptic vesicles from Torpedo electric organ." J. Neurochem. 51, 1465-1469 (1988).

17. M. Sbaschnig-Agler, K.H. Pfenninger, and R.W. Ledeen, "Gangliosides and other lipids of the growth cone membrane." J. Neurochem. 51, 212-220 (1988).

18. K.K. Vaswani and R.W. Ledeen, "Purified rat brain myelin contains measurable acyl-CoA: lysophospholipid acyltransferase (s) but little, if any, glycerol3-phosphate acylatransferase." J. Neurochem. 52, 69-74 (1989).
19. R.K. Yu, L.J. Macala, M. Farooq, M. SbaschnigAgler, W.T. Norton, and R.W. Ledeen, "Ganglioside and lipid composition of bulk-isolated rat and bovine oligodendroglia." J. Neurosci. Res., 23, 136-141 (1989).

20. G. Wu, K.K. Vaswani, Z.-H. Lu, and R.W. Ledeen, "Gangliosides stimulate calcium flux in neuro-2A cells and require exogenous calcium for neuritogenesis." J. Neurochem. 55, 484-491 (1990).

21. G. Wu and R.W. Ledeen, "Stimulation of neurite outgrowth in neuroblastoma cells by neuraminidase: putative role of GM1 ganglioside in differentiation." J. Neurochem. 56, 95-104 (1991).

22. R.W. Ledeen, F. Golly, and J. Haley, "Axon myelin transfer of phospholipids and phospholipid precursors." Molecular Neurobiol. 6, 179-190 (1992).

23. G. Chakraborty and R.W. Ledeen, "Guanylyl cyclase activity in rat brain myelin and white matter." J. Neurochem. 61, 1953-1956 (1993).

24. R.W. Ledeen, M.F. Diebler, G. Wu, Z-H Lu, and H. Varoqui, "Ganglioside composition of subcellular fractions, including pre- and postsynaptic membranes, from torpedo electric organ." Neurochem. Res. 18, 1151-1155 (1993).

25. G. Wu, Z.-H Lu, and R.W. Ledeen, "Induced and spontaneous neuroitogenesis are associated with enhanced expression of gangliside GM1 in the nuclear membrane. J. Neurosci. 15, (1995).

26. G. Wu, Z.-H. Lu, and R.W. Ledeen, "GM1 ganglioside in the nuclear membrane modulates nuclear calcium homeostasis during neurite outgrowth". J. Neurochem. 65, 1419-1422 (1995).

27. G. Wu, Z. -H Lu, P. Alfinito, and R.W. Ledeen, "Opioid receptor and calcium channel regulation of adenylyl cyclase, modulated by GM1, in NG108-15 cells: competitive interactions". Neurochem. Res. 22, 1281-1289 (1997).

28. G. Chakraborty, S. Ziemba, A. Drivas, and R.W. Ledeen, "Myelin contains neutral sphingomyelinase activity that is stimulated by tumor necrosis factor- $\alpha$ ". J. Neurosci. Res. 50, 466-476 (1997).

29. G. Wu, Y. Fang, Z. -H Lu, and R.W. Ledeen, "Induction of axon-like and dendrite-like processes in neuroblastoma cells". J. Neurocytol. 27, 1-14 (1998).

30. G. Chakraborty, A. Drivas, and R.W. Ledeen, "The phoshpinositide signaling cycle in myelin requires cooperative interaction with the axon". Neurochem. Res. 24, 249-254 (1999).

31. G. Wu, X. Xie, Z.-H. Lu, and R.W. Ledeen, "Cerebellar neurons lacking complex gangliosides degenerate in the presence of depolarizing levels of potassium". Proc. Natl. Acad. Sci. USA 98, 307-312 (2001). 
32. G. Chakraborty, P. Mekala, D. Yahya, G. Wu and R.W. Ledeen, "Intraneuronal N-acetylaspartate supplies acetyl groups for myelin lipid synthesis: evidence for myelin-associated aspartoacylase." J. Neurochem. 78, 736-745 (2001).

33. X. Xie, G. Wu, Z.-H. Lu, and R.W. Ledeen, "Potentiation of a sodium-calcium exchanger in the nuclear envelope by nuclear GM1 ganglioside." J. Neurochem. 81, 1185-1195 (2002).

34. G. Wu, Z.-H. Lu, J. Wang, Y. Wang, X. Xie, M.F. Meyenhofer, and R.W. Ledeen, "Enhanced susceptibility to kainite-induced seizures, neuronal apoptosis, and death in mice lacking gangliotetraose gangliosides. Protection with LIGA20, a permeant analog of GM1". J. Neurosci. 23, 11014-11022 (2006).

35. J. Wang, R. Matalon, G. Bhatia, G. Wu, H. Li, T. Liu, Z-H. Liu, and R.W. Ledeen, "Bimodal occurrence of aspartoacylase in myelin and cytosol of brain". J. Neurochem. 101, 448-457 (2007).

36. G. Wu, Z.-H. Lu, A.G. Obukhov, M.C. Nowycky, and R.W. Ledeen, "Induction of calcium influx through TRPC 5 channels by cross-linking of GM1 ganglioside associated with alpha5beta1 integrin initiates neurite outgrowth." J. Neurosci. 27, 7447-7458 (2007).
37. J. Wang, Z-H. Lu, H-J. Gabius, C. RohowskyKochan, R.W. Ledeen, and G. Wu, "Cross-Linking of GM1 ganglioside by galectin-1 mediates regulatory $\mathrm{T}$ cell activity involving TRPC5 channel activation: possible role in suppressing experimental autoimmune encephalomyelitis." J. Immunol. 182: 4036-4045 (2009).

38. G. Wu, X. Xie, Z-H. Lu, and R.W. Ledeen, "Sodiumcalcium exchanger complexed with GM1 ganglioside in nuclear membrane transfers calcium to endoplasmic reticulum". Proc. Natl Acad. Sci USA 106: 10829-10834 (2009).

39. G. Wu, Z.-H. Lu, N. Kulkarni, R. Amin, and R.W. Ledeen, "Mice lacking major brain gangliosides develop Parkinsonism". Neurochem. Research 36: 1706-1714 (2011).

40. G. Wu, Z.-H. Lu, H.-J. Gabius, R.W. Ledeen, and Bleich D, "Ganglioside GM1 deficiency in effector $\mathrm{T}$ cells from NOD mice induces resistance to regulatory T cell suppression”. Diabetes 60:2341-2349 (2011).

41. R.W. Ledeen and G. Wu, "Neurobiology meets glycosciences" in The Sugar Code. Fundamentals of Glycosciences (ed. by H.-J. Gabius) Wiley-VCH; pp. 495-516 (2009). 